\title{
El dominio fiduciario, los embargos en forma de retención y el deudor cedido
}

Diego Alberto Uribe Mendoza

Abogado por la Universidad de Lima. 


\section{RESUMEN:}

El dominio fiduciario sobre un patrimonio fideicometido no responde por las deudas que puedan tener el fideicomitente, fiduciario $y$, de ser el caso, fideicomisario frente a terceros. La obligación de retención emitida por medio de una resolución coactiva de embargo en forma de retención no recae sobre los bienes y/o derechos que se encuentran transferidos en dominio fiduciario de forma previa a la efectividad de la misma. La errónea interpretación de las normas tributarias y el desconocimiento de la figura del fideicomiso, no solo debilita la confianza sobre nuestras instituciones sino también pone en riesgo la seguridad del dominio fiduciario sobre un patrimonio autónomo.

Palabras clave: Dominio fiduciario, patrimonio fideicometido, embargo, retención, obligaciones.

\footnotetext{
ABSTRACT:

The trust fund cannot be affected by the debts that the settlor, the trustee, or the beneficiary, —if applicable —, may have before third parties. An order to withhold funds is not effective against assets or rights held in trust as fiduciary ownership. The misinterpretation of tax regulations and the unawareness of the trust institution, not only weakens the confidence in our institutions, but also jeopardizes the reliability of the fiduciary domain over an autonomous estate.

Keywords: Fiduciary domain, trust fund, lien, retention, obligations.
}

\section{INTRODUCCIÓN}

Si bien existen diversos artículos que desarrollan el aspecto teórico de los fideicomisos, son pocos aquellos que se detienen a regular la casuística a la que se enfrentan y los diversos aspectos que se deben tomar en cuenta al momento de estructurar una operación que tiene como garantía colateral un contrato de fideicomiso. Este artículo tiene como objeto desarrollar las contingencias que afronta un patrimonio fideicometido constituido por derechos de cobro - derecho a exigir el pago-y flujos dinerarios - dinero que proviene de dichos derechos de cobro-, frente al embargo en forma de retención al cual se ve expuesto por desconocimiento de las normas pertinentes.

Para tener claro este tema, es importante repasar la estructura básica del fideicomiso. Al respecto, resulta necesario citar el artículo $241^{1}$ de la Ley General del Sistema Financiero y del Sistema de Seguros y Orgánica de la Superintendencia de Banca y Seguros - en adelante, "Ley de Bancos" - el cual desarrolla el concepto del fideicomiso, señalando en otras palabras que, con la celebración de un contrato de fideicomiso, el fideicomitente - deudor - transfiere bienes en dominio fiduciario a otra persona, denominada fiduciario - tercero ajeno a la relación entre acreedor y deudor-, para la constitución de un patrimonio fideicometido, sujeto a la administración del fiduciario y afecto al cumplimiento de un fin específico en favor del fideicomitente o un tercero denominado fideicomisario - acreedor-. En otras palabras, con la celebración de un contrato de fideicomiso, el fideicomitente transfiere bienes $y / 0$ derechos de su titularidad a un patrimonio autónomo que se denomina patrimonio fideicometido, el

1. "Artículo 241.-

El fideicomiso es una relación jurídica por la cual el fideicomitente transfiere bienes en fideicomiso a otra persona, denominada fiduciario, para la constitución de un patrimonio fideicometido, sujeto al dominio fiduciario de este último y afecto al cumplimiento de un fin específico en favor del fideicomitente o un tercero denominado fideicomisario.

El patrimonio fideicometido es distinto al patrimonio del fiduciario, del fideicomitente, o del fideicomisario y en su caso, del destinatario de los bienes remanentes. Los activos que conforman el patrimonio autónomo fideicometido no generan cargos al patrimonio efectivo correspondiente de la empresa fiduciaria, salvo el caso que por resolución jurisdiccional se le hubiera asignado responsabilidad por mala administración, y por el importe de los correspondientes daños y perjuicios. La parte líquida de los fondos que integran el fideicomiso no está afecta a encaje.

La Superintendencia dicta normas generales sobre los diversos tipos de negocios fiduciarios." 
cual es administrado por un fiduciario, con la finalidad de cumplir un fin específico en favor del mismo fideicomitente o de un fideicomisario.

La celebración de un contrato de fideicomiso y la consecuente constitución de un patrimonio fideicometido se utiliza en nuestro país de manera frecuente en operaciones donde los fideicomisarios son, en gran mayoría, entidades del sistema financiero y del mercado de valores - bancos, cajas, fondos de inversión, entre otros-; dado que dicha figura permite que la garantía sea administrada por el fiduciario otorgándoles una protección distinta a la que pueda ofrecer las garantías tradicionales.

Teniendo claro el concepto del fideicomiso y, sobre todo, lo relevante de lo establecido en el artículo $253^{2}$ de la Ley de Bancos, durante los últimos años los patrimonios fideicometidos que tienen como bienes fideicometidos derechos de cobro y flujos dinerarios que provienen de un tercero, se han visto expuestos a interpretaciones que transgreden lo dispuesto por nuestro ordenamiento jurídico. En muchas ocasiones, a pesar que el citado artículo de la Ley de Bancos es claro, los flujos dinerarios se han visto expuestos a embargos en forma de retención utilizando como argumentos alegaciones arbitrarias y, en ciertos casos, irrazonables.

Cabe recalcar que, si bien el embargo en forma de retención puede darse bajo un proceso judicial dictado bajo las normas competentes, el desarrollo de este artículo está enfocado en los inconvenientes que se han presentado con los ejecutores coactivos de la Superintendencia Nacional de Aduanas y de Administración Tributaria - SUNAT- y la actuación de los terceros obligados a retener una vez que han sido notificados con una resolución coactiva de manera posterior a la constitución de un patrimonio fideicometido.

Para plantear el problema y su respectiva solución, se debe hacer hincapié en tres conceptos: el dominio fiduciario, el embargo en forma de retención y la participación del deudor cedido.

\section{EL DOMINIO FIDUCIARIO}

Es importante destacar las facultades que confiere el dominio fiduciario al fiduciario y la protección que deriva de ello, porque a pesar que la norma es clara en ese sentido, se pretende desconocer y limitar sus alcances, desnaturalizando al fideicomiso, lo cual lo afecta gravemente.

El ejercicio que realiza el fiduciario sobre los bienes que se encuentran dentro del patrimonio fideicometido es denominado dominio fiduciario, el cual tiene como fin específico lo establecido en el acto constitutivo - contrato de fideicomiso- y que se lleva a cabo a favor del fideicomisario o del propio fideicomitente. Lo comentado se encuentra desarrollado en el artículo 252 de la Ley de Bancos ${ }^{3}$, donde el legislador estableció que el dominio fiduciario

2. "Artículo 253.-

El patrimonio fideicometido no responde por las obligaciones del fiduciario o del fideicomitente ni de sus causahabientes $y$, tratándose de las obligaciones de los fideicomisarios, tal responsabilidad sólo es exigible sobre los frutos o las prestaciones que se encuentran a disposición de ellos, de ser el caso."

3. "Artículo 252.-

El fiduciario ejerce sobre el patrimonio fideicometido, dominio fiduciario, el mismo que le confiere plenas potestades, incluidas las de administración, uso, disposición y reivindicación sobre los bienes que conforman el patrimonio fideicometido, las mismas que son ejercidas con arreglo a la finalidad para la que fue constituido el fideicomiso, y con observancia de las limitaciones que se hubieren establecido en el acto constitutivo.

Dependiendo de la naturaleza del fideicomiso, el fideicomitente y sus causahabientes son titulares de un derecho de crédito personal contra el patrimonio fiduciario.

La empresa fiduciaria sólo puede disponer de los bienes fideicometidos con arreglo a las estipulaciones contenidas en el instrumento constitutivo. Los actos de disposición que efectúe en contravención de lo pactado son anulables, si el adquirente no actuó de buena fe, salvo el caso de que la transferencia se hubiese efectuado en una bolsa de valores. La acción puede ser interpuesta por cualquiera de los fideicomisarios, el fideicomitente y aún por la propia empresa fiduciaria." 
ejercido por el fiduciario sobre el patrimonio fideicometido le confiere plenas potestades, incluidas las de administración, uso, disposición y reivindicación sobre los bienes que conforman el patrimonio autónomo.

Para desarrollar este concepto, se debe tener en cuenta lo estipulado en el Reglamento del Fideicomiso y de las Empresas de Servicios Fiduciarios, aprobado por la Resolución SBS $\mathrm{N}^{\circ}$ 1010-99, el cual en su artículo 4, indica que:

"El dominio fiduciario es el derecho de carácter temporal que otorga al fiduciario las facultades necesarias sobre el patrimonio fideicometido, para el cumplimiento del fin o fines del fideicomiso, con las limitaciones establecidas en el acto constitutivo, según lo señalado en el artículo 252 de la Ley General. El dominio fiduciario se ejerce desde la transferencia de los bienes objeto del fideicomiso, salvo disposición contraria establecida en el acto constitutivo, hasta el término del fideicomiso."

Sumado a lo señalado, una vez que el fiduciario ejerce el dominio fiduciario sobre los bienes fideicometidos, tal cual lo señala el artículo 253 de la Ley de Bancos:

"(...) no responde por las obligaciones del fiduciario o del fideicomitente ni de sus causahabientes y, tratándose de las obligaciones de los fideicomisarios, tal responsabilidad sólo es exigible sobre los frutos o las prestaciones que se encuentran a disposición de ellos, de ser el caso."

Según Escobar:

"(...) quien tiene la posibilidad de actuar sobre los activos es el fiduciario y no el fideicomitente. Por consiguiente, este último no puede ser titular de los derechos en cuestión, ya que simplemente no ostenta facultas agendi alguna sobre los mismos. Por lo demás, según el ordenamiento positivo peruano, el patrimonio autónomo es distinto al patrimonio del fideicomitente. Siendo esto así, es claro que los activos que integran el primer patrimonio no forman parte del segundo, por lo que el fideicomitente no puede tener derecho alguno sobre tales activos." ${ }^{4}$

Queda claro que, una vez que el fiduciario adquiere el dominio fiduciario sobre los bienes transferidos al patrimonio fideicometido, las obligaciones del fideicomitente frente a terceros, incluido entidades del Estado, no pueden ni deben ser atendidas con los bienes transferidos en dominio fiduciario. Los bienes del patrimonio fideicometido ahora forman parte de un patrimonio autónomo que es distinto al patrimonio del fideicomitente y que solo será utilizado conforme a lo estipulado en el acto constitutivo.

\section{EL EMBARGO EN FORMA DE RETENCIÓN}

Conforme a lo señalado en el artículo 118 del Texto Único Ordenado del Código Tributario, aprobado por el Decreto Supremo No 133-2013$\mathrm{EF}$, nuestro ordenamiento le otorga al ejecutor coactivo la posibilidad de dictar medidas que aseguren la forma más adecuada para el pago de una deuda tributaria dentro de las cuales se encuentra el embargo en forma de retención. Pero, ¿qué significa el embargo en forma de retención? Tal cual lo menciona el propio nombre, la Administración Tributaria - a través del ejecutor coactivo- ordena, bajo responsabilidad, a los terceros que tengan en su poder bienes, valores y/o fondos en cuentas corrientes, depósitos, custodia y otros, así como sobre los derechos de crédito de los cuales el deudor tributario sea titular, los retengan y entreguen a la Administración Tributaria.

Es importante recalcar que los embargos en forma de retención son comunicados por la Administración Tributaria a través de resolu-

4. Freddy Escobar Rozas, "Breve ensayo sobre el dominio fiduciario en el sistema jurídico peruano", Thēmis 48 (2004): 85 - 103. 
ciones coactivas, donde disponen claramente el monto hasta por el cual los terceros deberán retener los derechos de crédito y/o bienes de titularidad del deudor tributario. Los embargos en forma de retención son temporales y pueden ser levantados por la misma autoridad, en la oportunidad y en los casos que corresponda, liberando a los terceros de la obligación de retención. Para que surtan efectos, tanto las resoluciones coactivas como las resoluciones de levantamiento de éstas, deben ser debidamente comunicadas a los terceros.

Otra de las características relevantes de esta figura, es que en el inciso 4 del artículo 118 del Código Tributario, se establece que "(...) el tercero no podrá informar al ejecutado de la ejecución de la medida hasta que se realice la misma".

De igual manera, en dicho inciso se establece que el tercero se encuentra obligado a poner en conocimiento del ejecutor coactivo si podrá llevar a cabo la retención o la imposibilidad de ésta. La imposibilidad de retención puede darse por diversos factores, dentro de los cuales, se encuentra que los bienes y/o derechos que están en poder de terceros hayan sido transferidos en dominio fiduciario por lo que no podrán ni deberán ser retenidos por dichos terceros, en virtud de que el patrimonio autónomo constituido previo a las notificaciones de los embargos en forma de retención, es el acreedor de dichos bienes y/o derechos.

\section{EL DEUDOR CEDIDO: LA RELEVANCIA DE LA DEBIDA NOTIFICACIÓN}

Para entender la figura del deudor cedido, es importante desarrollar el concepto de un contrato de fideicomiso que tiene como bienes fideicometidos derechos de cobro y flujos di- nerarios, también denominado fideicomiso de flujos. Dentro de esta estructura, tenemos a un fideicomitente que transfiere en dominio fiduciario el derecho de cobro y flujo dinerario que deriva de una relación jurídica con un tercero. Este derecho de cobro y flujo dinerario pasará a ser el bien que deberá ser administrados por el fiduciario, conforme a lo estipulado en el acto constitutivo. El derecho de cobro y flujo dinerario puede provenir de, entre otros, un servicio que el fideicomitente le brindó a un tercero, el cual tiene pendiente cancelar su contraprestación por el servicio prestado; así como de un contrato de arrendamiento donde el fideicomitente es el arrendador y el tercero es el arrendatario, entre otros. La figura del fideicomiso de flujos, en muchos casos, tiene como fin garantizar el pago de una facilidad crediticia otorgada por el fideicomisario a favor del fideicomitente.

Como se menciona en el párrafo precedente, más allá del fideicomitente, fiduciario y fideicomisario, existe un actor relevante que, en la gran mayoría de casos, no suscribe el contrato de fideicomiso de flujos, pero si tiene una participación activa dentro de la estructura, que es el tercero que tiene una deuda frente al fideicomitente y al cual se le denomina deudor cedido. Transferido el derecho de cobro y flujo dinerario en dominio fiduciario, a partir de la suscripción del contrato de fideicomiso, el nuevo acreedor del pago y/o amortizaciones de la deuda que tiene el deudor cedido frente al fideicomitente, es el patrimonio fideicometido, en virtud de la cesión de la titularidad de sus derechos ${ }^{5}$ a favor del patrimonio autónomo constituido.

Sin embargo, el deudor cedido no podría enterarse de dicha transferencia en dominio fiduciario a favor de un fideicomiso de flujos si es que no es informado de la existencia del mismo. ${ }^{6}$

5. Código Civil: "Artículo 1206.-

La cesión es el acto de disposición en virtud del cual el cedente transmite al cesionario el derecho a exigir la prestación a cargo de su deudor, que se ha obligado a transferir por un título distinto.

La cesión puede hacerse aun sin el asentimiento del deudor."

6. Código Civil: "Artículo 1215.- La cesión produce efecto contra el deudor cedido desde que éste la acepta o le es comunicada fehacientemente." 
Sin la debida comunicación de la transferencia en dominio fiduciario de los bienes fideicometidos $y$, por ende, cambio de titularidad del derecho de cobro y flujo dinerario, el deudor cedido no podrá cumplir su obligación de pago, lo cual implica poner en riesgo la garantía del fideicomisario y la estructura para la cual fue creado el patrimonio fideicometido se podría ver comprometida. Para evitar lo mencionado, es imperativo que el deudor cedido sea notificado de la cesión de la titularidad del derecho de cobro y flujo dinerario a favor del patrimonio fideicometido.

Respecto a la notificación del deudor cedido, lo más adecuado es que ésta sea conjunta: es decir, que la suscriban el fideicomitente - cedentey el fiduciario - cesionario-. La comunicación conjunta evita que la obligación recaiga solo sobre el fideicomitente, disminuyendo el riesgo de la no comunicación al deudor cedido y que por ende dicho flujo no sea debidamente canalizado a través del patrimonio fideicometido. Sumado a lo mencionado, otra práctica usual es que, con el fin de mitigar aún más el riesgo de la no comunicación al deudor cedido, las partes acuerdan que, conjuntamente con la suscripción del contrato de fideicomiso, la comunicación al deudor cedido sea suscrita tanto por el fideicomitente como por el fiduciario con el fin de realizar la debida notificación.

Complementando lo señalado, la comunicación al deudor cedido implica que la cesión de la titularidad del derecho y flujo dinerario surta efectos desde que el deudor cedido es puesto en conocimiento de manera fehaciente. En caso el deudor cedido sea un privado, para obtener di- cha certeza y, sobre todo la fecha cierta en la cual fue notificado el deudor cedido, se recomienda utilizar el conducto notarial, el cual dejará constancia que el deudor cedido ha sido notificado de manera fehaciente $y$; por consiguiente, el inicio de los efectos de dicha cesión a favor del patrimonio fideicometido.? Respecto al caso en que el deudor cedido sea una entidad pública, bastará con la sola presentación en mesa de partes para generar la eficacia jurídica pertinente.

No obstante a lo mencionado en este punto, todo lo indicado aplica en el supuesto que, en la relación jurídica entre el deudor cedido y el fideicomitente, no exista la necesidad de una previa aprobación de la cesión de los derechos a favor de un tercero ${ }^{8}$ por parte del deudor cedido. De no ser así, será necesario que el deudor cedido manifieste explícitamente su aceptación a la cesión, de lo contrario el derecho de cobro y flujo dinerario no habrán sido transferidos en dominio fiduciario.

\section{DE LOS EMBARGOS EN FORMA DE RE- TENCIÓN A BIENES QUE CONFORMAN UN PATRIMONIO FIDEICOMETIDO}

Teniendo los conceptos desarrollados en el presente artículo, quedaría claro que no se pueden embargar derechos de cobro y flujos dinerarios que han sido transferidos a un patrimonio fideicometido. Sin embargo, esto no ocurre siempre, ya que - a pesar de que nuestro ordenamiento legal es claro- se pretende desconocer que los bienes transferidos en dominio fiduciario no responden por las deudas del fideicomitente, fiduciario ni fideicomisario, lo cual hace que los bienes

7. Código Procesal Civil: "Artículo 245.- Un documento privado adquiere fecha cierta y produce eficacia jurídica como tal en el proceso desde:

1. La muerte del otorgante;

2. La presentación del documento ante funcionario público;

3. La presentación del documento ante notario público, para que certifique la fecha o legalice las firmas;

4. La difusión a través de un medio público de fecha determinada o determinable; y

5. Otros casos análogos."

8. Código Civil:

"Artículo 1210.- La cesión no puede efectuarse cuando se opone a la ley, a la naturaleza de la obligación o al pacto con el deudor. El pacto por el que se prohíbe o restringe la cesión es oponible al cesionario de buena fe, si consta del instrumento por el que se constituyó la obligación o se prueba que el cesionario lo conocía al momento de la cesión." 
antes citados se vean expuestos a interpretaciones erróneas por parte de los deudores cedidos.

El deudor cedido en estos escenarios vuelve a tomar una participación muy relevante, dado que es a ellos a quienes notifica el ejecutor coactivo con el fin que procedan con la retención de los bienes y/o derechos que puedan tener en su poder que correspondan al deudor tributario. Ante este escenario, el deudor cedido debería responderle al ejecutor coactivo indicándole la imposibilidad de llevar a cabo dicha orden ${ }^{9}$ dado que los bienes han sido transferidos en dominio fiduciario a un patrimonio fideicometido constituido previo a la notificación de la resolución coactiva. Lo mencionado es lo que el deudor cedido debería llevar a cabo; sin embargo, esto no siempre sucede así. En diversas ocasiones, el deudor cedido ha procedido con la retención y entrega de los bienes del patrimonio fideicometido a la autoridad tributaria, antes que entregarlo al patrimonio fideicometido conforme a lo que nuestro ordenamiento jurídico demanda. En este momento es que nos enfrentamos a la interpretación errónea del deudor cedido, dado que la resolución coactiva recae sobre los bienes y/o derechos del deudor tributario - fideicomitente- y no sobre el patrimonio fideicometido.

La decisión del deudor cedido de entregar los bienes y/o derechos de titularidad del patrimonio fideicometido para responder por una deuda del fideicomitente a la autoridad tribu- taria, sin haber advertido - lo cual sería una negligencia grave- o habiendo advertido - lo cual sería dolo- que el bien y/o derecho retenido no eran de propiedad del fideicomitente, conlleva a que el fiduciario active la defensa del patrimonio fideicometido y proceda con iniciar las acciones legales pertinentes contra el deudor cedido que fue debidamente notificado.

El deudor cedido está legalmente obligado a reconocer, bajo responsabilidad de la institución y de sus funcionarios, que dichos bienes forman parte de un patrimonio fideicometido administrado por un fiduciario y a respetar a cabalidad lo imperativamente establecido al respecto en el artículo 253 de la Ley de Bancos. De hecho, afectar un patrimonio fideicometido para la satisfacción y ejecución forzosa de deudas de un fideicomitente, como lo han hecho en diversas ocasiones los deudores cedidos, constituye un accionar abusivo y violatorio del texto claro y expreso de la Ley de Bancos en los extremos antes citados, lo cual determina que tanto el deudor cedido como sus funcionarios incurran en responsabilidad.

\section{CONCLUSIONES}

Los derechos de cobro y flujos dinerarios cedidos en dominio fiduciario, se ven expuestos a resoluciones coactivas que establecen embargos en forma de retención; o peor aún, establecen medidas de otro tipo ${ }^{10}$, yendo en contra de

9. Código Tributario:

"Artículo 118.-

(...)

4. En forma de retención, en cuyo caso recae sobre los bienes, valores y fondos en cuentas corrientes, depósitos, custodia y otros, así como sobre los derechos de crédito de los cuales el deudor tributario sea titular, que se encuentren en poder de terceros.

La medida podrá ejecutarse mediante la diligencia de toma de dicho o notificando al tercero, a efectos que se retenga el pago a la orden de la Administración Tributaria. En ambos casos, el tercero se encuentra obligado a poner en conocimiento del Ejecutor Coactivo la retención o la imposibilidad de ésta en el plazo máximo de cinco (5) días hábiles de notificada la resolución bajo pena de incurrir en la infracción tipificada en el numeral 5) del Artículo 177. (...)"-el subrayado es nuestro-.

10. Informe $N^{\circ}$ 254-2005-SUNAT/2B0000: "En el marco de los contratos de fideicomiso, celebrados al amparo de la Ley de Banca y Seguros, no procede trabar medidas cautelares sobre los bienes y derechos transferidos por el deudor tributario, en calidad de fideicomitente, para que integren un patrimonio fideicometido; salvo que dichas medidas hayan surtido efecto con anterioridad a la transferencia fideicomisaria de tales bienes y/o derechos." 
todo lo establecido en nuestro ordenamiento $y$, en particular, en los conceptos desarrollados en este artículo.

No resulta jurídicamente posible ni válido que se afecten bienes de un patrimonio fideicometido para satisfacer deudas del fideicomitente, tal como lo ha hecho en diversas ocasiones los deudores cedidos y las autoridades competentes, incurriendo en una grave arbitrariedad generando un perjuicio al patrimonio autónomo constituido y, en particular, a la figura del fideicomiso.

¿Es un patrimonio fideicometido inembargable? Sí, sí lo es siempre y cuando se cumpla con lo señalado en este artículo. La regla respecto a la imposibilidad de encontrarse afecto a la re- solución coactiva que plantea un embargo en forma de retención frente a un deudor cedido, es bastante sencilla: la constitución del patrimonio fideicometido y la notificación al deudor cedido, deben ser previos a que las medidas determinadas hayan surtido efecto.

Lo mencionado no busca, bajo ningún supuesto, limitar o restringir el actuar de un ejecutor coactivo, por el contrario, lo establecido por nuestro ordenamiento jurídico es claro. El ejecutor coactivo tiene la facultad jurídica de trabar embargos en forma de retención sobre bienes y/o derechos de un deudor tributario que se encuentre en poder de un tercero; sin embargo, esto no aplica cuando dichos bienes y/o derechos han sido transferidos en dominio fiduciario con anterioridad a la medida. 